\title{
ANALISIS FAKTOR-FAKTOR PENYEBAB PEKERJAAN ULANG (REWORK) \\ PADA PROYEK KONSTRUKSI BANGUNAN GEDUNG DI KOTA KUPANG
}

\author{
Gregorius Pius Usboko $^{1}$, Sebastianus Baki Henong ${ }^{2}$ \\ 1,2 Dosen Program Studi Teknik Sipil Fakultas Teknik Unwira Kupang \\ *correspondent Author : sebasthenong00@gmail.com
}

\begin{abstract}
Implementation of a building construction project carried out through a certain management system. The project has a predetermined schedule and implementation plan. Common things that will occur if they are not in accordance with the schedule and implementation plan are delays in project implementation time and implementation costs. One of the factors causing the delay is due to rework activities on one or several items of construction work. The purpose of this study was to identify and analyze the factors that cause rework on building construction projects in the city of Kupang, East Nusa Tenggara Province. This study used a questionnaire instrument involving as many as 27 contractors, consisting of 12 site managers, 12 field implementers and 3 foreman. This research was conducted to see the dominant factor of rework in building construction projects in Kupang city. The results showed that the factors causing rework are known from managerial, design and resource factors which are the main causes of the emergence of rework in work. Operators working not according to procedures are one of the main causes of rework from the resource factor. Lack of teamwork is the cause of the rework of managerial factors. Unclear design or documentation is the cause of rework of design factors.
\end{abstract}

Keyword : Rework, Building, Kupang City

\begin{abstract}
ABSTRAK
Penyelenggaraan proyek konstruksi suatu bangunan dilaksanakan melalui sistem manajemen proyek tertentu. Proyek konstruksi mempunyai jadwal dan rencana pelaksanaan yang telah ditentukan. Dampak umum yang akan terjadi apabila tidak sesuai dengan jadwal dan rencana pelaksanaan yakni keterlambatan waktu pelaksanaan proyek serta meningkatnya biaya pelaksanaan. Salah satu faktor penyebab keterlambatan tersebut adalah karena adanya aktivitas pekerjaan ulang (rework) pada satu atau beberapa item pekerjaan konstruksi. Tujuan penelitian ini adalah untuk mengetahui dan menganalisis faktor-faktor yang menjadi penyebab rework pada proyek konstruksi gedung di kota Kupang Provinsi Nusa Tenggara Timur. Penelitian ini menggunakan instrumen kuisioner yang melibatkan responden sebanyak 27 orang kontraktor, terdiri dari 12 orang site manager, 12 orang pelaksana lapangan dan 3 orang mandor. Penelitian ini dilakukan untuk melihat faktor dominan rework pada proyek pembangunan gedung di kota Kupang. Hasil penelitian menunjukan bahwa faktor-faktor penyebab rework diketahui dari faktor manajerial, desain dan sumber daya yang merupakan penyebab utama munculnya rework dalam pekerjaan. Operator bekerja tidak sesuai dengan prosedur merupakan salah satu penyebab utama rework dari faktor sumber daya. Kurangnya teamwork merupakan penyebab rework dari faktor manajerial. Desain atau dokumentasi yang tidak jelas merupakan penyebab rework dari faktor desain.
\end{abstract}

Kata kunci : Pekerjaan ulang, rework, bangunan gedung, kota Kupang

\section{PENDAhUluan}

Rework adalah pekerjaan ulang yang diakhibatkan karena kesalahan-kesalahan dari suatu proyek konstruksi. Dalam suatu kegiatan konstruksi hampir selalu terjadi yang namanya rework hanya saja kualitasnya yang berbeda-beda. Rework 
bisa ditimbulkan karena dalam pelaksanaan suatu proyek tidak memperhatikan kualitas dari proyek yang sedang dikerjakan. Hasilnya adalah produk di bawah standar dan sering terjadi perbaikan-perbaikan yang menimbulkan rework.

Analisis ini secara khusus digunakan untuk mengetahui faktor-faktor penyebab rework pada pelaksanaan proyek konstruksi di Kota Kupang. Setelah mengetahui dengan jelas faktor-faktor penyebab rework ini, maka dapat dicari strategi-strategi efektif yang dapat digunakan untuk mencegah adanya rework. Dengan demikian diharapkan dapat meningkatkan performa dan kualitas dari suatu proyek yang sedang berjalan tersebut.

Kota kupang merupakan ibukota propinsi NTT dan merupakan ibu kota kabupaten ternama di Propinsi NTT. Berdasarkan catatan Pos Kupang (selasa, 12 januari 2016), ternyata ada begitu banyak proyek konstruksi bangunan gedung yang mengalami keterlambatan waktu karena berbagai macam persoalan dan salah satunya adalah pekerjaan ulang (rework). Dari catatan tersebut terdapat lima paket proyek yang belum selesai dikerjakan akhibat kesulitan memperoleh bahan bangunan seperti semen dan batu pecah. Oleh karena itu waktu pekerjaan diperpanjang.

Hasil dari penelitian ini diharapkan dapat bermanfaat dan dijadikan bahan masukan bagi para pengambil keputusan dan penyelenggara proyek yang ada di Kota Kupang agar dampak dari pekerjaan ulang (rework) dapat diantisipasi di masa yang akan datang.

\section{TINJAUAN PUSTAKA}

Dalam bahasa Indonesia kata rework diterjemahkan menjadi pekerjaan ulang. Rework sudah menjadi bagian yang hampir tak terpisahkan dalam dunia konstruksi. Oleh karena itu banyak peneliti yang mengadakan riset dan penelitian untuk mengetahui apa sebenarnya rework dalam dunia konstruksi dan penyebab dari rework tersebut.

Dalam studi yang dilakukan oleh Love (2002), sumber rework dikategorikan dalam empat kategori yaitu change, error, omission, dan damage. Kategori ini sebelumnya telah digunakan oleh Farrington (1987), sedangkan pada penelitian yang dilakukan oleh Sommerville mengkategorikannya menjadi tiga yakni change, error dan omission. Ketiga kategori ini dapat terjadi mulai dari pelaksanaan desain sampai dengan konstruksi berlangsung.

a. Perubahan (Change). Tindakan yang dilakukan karena adanya perintah kerja. Perubahan bisa dikategorikan tidak termasuk rework apabila pekerjaan tersebut telah disetujui owner. Biasanya yang termasuk change adalah penurunan kualitas (defect), tidak adanya pemberitahuan/persetujuan atas perubahan, kesalahan dan cacat pada saat pengerjaan.

b. Kesalahan (error). Kegiatan dalam proses kerja yang dilakukan secara tidak benar sehingga mengakhibatkan hasil kerja menyimpang dari rancangan awal.

c. Kelalaian (ommision). Semua kegiatan yang termasuk penangguhan, ketidaksadaran, menelantarkan dan kelengahan yang menyebabkan terjadinya kerusakan/cacat. 
Adapun jenis-jenis rework yang melandasi penelitian ini. Penentuan variabel jenis-jenis rework diambil dari literature : Burati, Farington, dan Ledbetter (1992) yakni :

1. Repair. Sesuai definisi pada tinjauan pustaka, lingkup repair adalah pekerjaan ulang untuk mengembalikan kondisi item pekerjaan tertentu ke kondisi semula. (pekerjaan dimaksud sudah berada dalam kondisi selesai)

2. Revision. Lingkup pada revision adalah sesuai definisi yaitu pekerjaan yang dilakukan untuk menyelesaikan atau menyempurnakan item pekerjaan dimaksud yang mengalami perubahan-perubahan akhibat pelaksanaan pekerjaan finishing perumahan.

3. Replacement. Merupakan aktifitas perbaikan dengan mengganti suatu unit material, sistem karena tidak berfungsi sesuai standar.

4. Redesign. Merupakan aktifitas perbaikan yang dilakukan perancang atau pelaksana untuk merancang ulang design finishing.

\section{Metodologi Penelitian}

Sasaran utama yang ada pada proyek konstruksi adalah tepat waktu, tepat mutu/spesifikasi dan tepat biaya. Karakteristik proyek yang unik sementara dan dinamis menyebabkan timbulnya kejadian yang bersifat tidak pasti dalam pelaksanaannya, dimana ketidakpastian tersebut menimbulkan resiko. Dalam pelaksanaan proyek konstruksi, ketidakpastian dan resiko selalu melekat dalam kegiatan proyek konstruksi. Dampak negatif dari ketidakpastian dan resiko dapat menyebabkan tidak tercapainya sasaran proyek konstruksi yang salah satunya adalah terjadinya pekerjaan ulang (rework) dalam pelaksanaan pembangunan proyek konstruksi.

Pekerjaan ulang pada pelaksanaan proyek konstruksi selalu menimbulkan dampak yang merugikan kontraktor, karena pekerjaan ulang dapat menyebabkan bertambahnya biaya pekerjaan (pekerja dan material) akhibat terjadinya pengulangan pekerjaan yang harus dikerjakan lebih dari sekali. Penelitian dilakukan untuk mengetahui faktor-faktor apa saja yang menyebabkan pekerjaan ulang pada pelaksanaan proyek konstruksi bangunan gedung yang ada di kota Kupang Propinsi Nusa Tenggara Timur. Untuk memperoleh gambaran yang jelas dan sistematis tentang metode penelitian dan langkah-langkah pelaksanaan dapat dilihat pada diagram alir berikut.

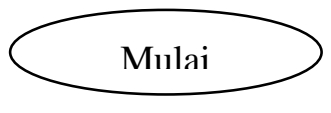


Vol 3 No 1 (2022), February 2022, pp. 13-23

(C)2022 Jurnal Teknik Sipil Cendekia
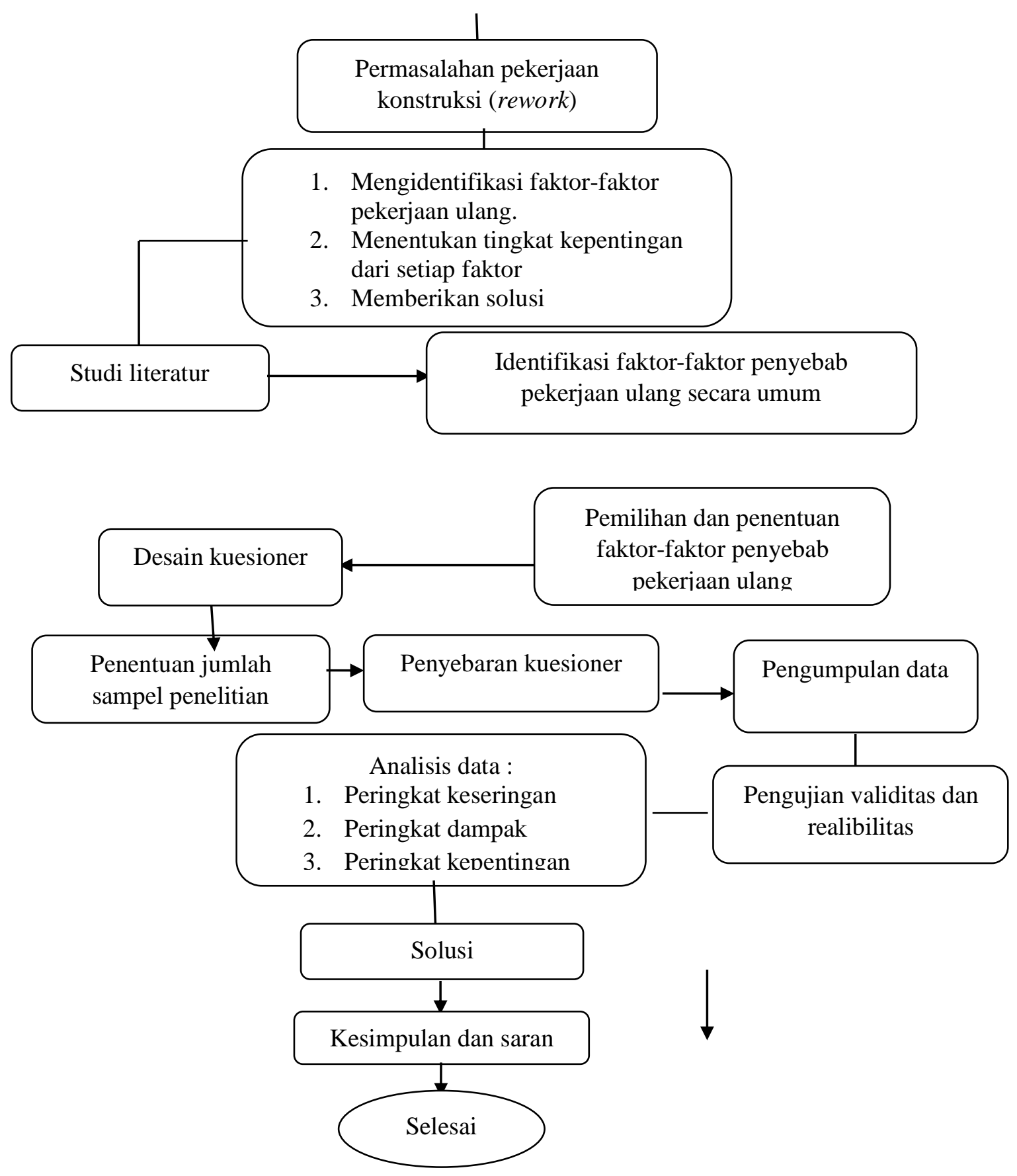

Gambar 1. Diagram alur penelitian

\section{ANALISA DAN PEMBAHASAN}

Data yang dikumpulkan dalam penelitian ini diperoleh dari kuesioner yang disebarkan kepada pihak kontraktor yang berada di kota Kupang propinsi Nusa tengggara Timur. Pendistribusian kuesioner dilakukan dalam kurun waktu pertengahan mei sampai pertengahan september 2016, yang dilakukan dengan 
penyampaian langsung. Sebanyak 30 kuesioner yang didistribusikan kepada pihak kontraktor, yang diisi dan dikembalikan adalah sebanyak 27 kuesioner. Berdasarkan hasil perhitungan maka diperoleh respon rate adalah sebesar $90 \%$.

Peringkat Faktor Penyebab Pekerjaan Ulang Berdasarkan Frequency

Peringkat faktor penyebab terjadinya pekerjaan ulang berdasarkan seberapa sering terjadinya frekuensi pekerjaan ulang pada proyek bangunan gedung yang ada di Kota Kupang dapat dilihat pada tabel di bawah ini. Untuk faktor penyebab pekerjaan ulang nomor 1, Menurut pendapat saudara/i seberapa sering terjadinya kesalahan atau ketidakjelasan desain dan dokumentasi gambar sehingga terjadinya pekerjaan ulang. Jawaban yang diperoleh yakni :

Yang menjawab 'angka 1' = 9 orang (bobot 1 )

Yang menjawab 'angka 2' $=8$ orang (bobot 2)

Yang menjawab 'angka 3' $=8$ orang (bobot 3)

Yang menjawab 'angka 4' $=1$ orang (bobot 4)

Yang menjawab 'angka 5' $=1$ orang (bobot 5)

FI $(\%)=\sum_{j=1}^{5} \mathrm{ax}\left(\begin{array}{l}n \\ N\end{array}\right) \times 100 / 5$

FI $(\%)=[1 \times(9 / 27)+2 \times(8 / 27)+3 \times(8 / 27)+4 \times(1 / 27)+5 \times(1 / 27)] \times 100 / 5$

FI $(\%)=\mathbf{4 2 . 9 6 \%}$

Tabel 3 Peringkat faktor-faktor penyebab rework berdasarkan frequency index

\begin{tabular}{|c|c|c|c|c|}
\hline $\begin{array}{c}\text { Grou } \\
\text { p }\end{array}$ & No & Variabel-variabel Penyebab Pekerjaan Ulang & FI (\%) & Rank FI \\
\hline I & 1 & Desain atau dokumentasi yang tidak jelas & 42.96 & 18 \\
\hline \multirow[t]{5}{*}{ II } & 2 & Jadwal terlalu padat (banyak pekerjaan lembur) & 54.81 & 12 \\
\hline & 3 & Ketidaksesuaian spesifikasi material & 43.71 & 17 \\
\hline & 4 & Kurangnya antisipasi terhadap keadaan alam & 34.07 & 19 \\
\hline & 5 & Buruknya alur informasi & 66.67 & 9 \\
\hline & 6 & Kurangnya teamwork & 68.88 & 6 \\
\hline \multirow[t]{18}{*}{ III } & 7 & Pekerja kurang berkompeten & & \\
\hline & A & Kurangnya pengalaman kerja & & \\
\hline & & a. Kurangnya pengalaman kerja Tukang & 62.96 & 10 \\
\hline & & b. Kurangnya pengalaman kerja mandor & 68.14 & 8 \\
\hline & & $\begin{array}{l}\text { c. Kurangnya pengalaman kerja pengawas } \\
\text { lapangan }\end{array}$ & 77.04 & 3 \\
\hline & & $\begin{array}{ll}\text { d. } & \text { Kurangnya pengalaman kerja operator }\end{array}$ & 69.62 & 5 \\
\hline & B & Kesalahan dalam menginterpretasikan gambar & & \\
\hline & & a. Pengawas lapangan & 44.44 & 16 \\
\hline & & b. $\quad$ Mandor & 44.44 & 16 \\
\hline & & c. Tukang & 68.15 & 7 \\
\hline & $\mathrm{C}$ & Bekerja tidak sesuai dengan prosedur kerja & & \\
\hline & & $\begin{array}{ll}\text { a. } & \text { Tukang } \\
\end{array}$ & 79.26 & 2 \\
\hline & & b. Operator & 84.44 & 1 \\
\hline & 8 & Kurangnya pengawasan & & \\
\hline & & a. Pengawas lapangan & 51.11 & 13 \\
\hline & & b. Mandor & 49.62 & 14 \\
\hline & 9 & Kurangnya komunikasi & & \\
\hline & & a. Owner dengan kontraktor & 46.67 & 15 \\
\hline
\end{tabular}




\begin{tabular}{|l|l|l|c|c|}
\hline & b. Pengawas lapangan dengan mandor & 57.78 & 11 \\
\hline & c. Pengawas lapangan dengan operator & 71.12 & 4 \\
\hline
\end{tabular}

Sumber : Hasil analisis

\section{A. Peringkat Faktor Penyebab Pekerjaan Ulang Berdasarkan Severity}

Peringkat yang diperoleh berdasarkan dampak yang timbul dari faktor-faktor penyebab pekerjaan ulang pada pekerjaan bangunan gedung yang ada di Kota Kupang dapat dilihat pada tabel dibawah ini. Untuk faktor penyebab pekerjaan ulang dengan nomor 1, Menurut pendapat saudara dan saudari seberapa besar dampak kerusakan pekerjaan akibat desain atau dokumentasi yang tidak jelas sehingga terjadi pekerjaan ulang, jawaban yang diperoleh dari responden yakni :

$$
S I(\%)=\sum_{j=1}^{5}\left(\mathrm{a} \times \frac{n}{N} \times 100 / 5\right)
$$

SI $(\%)=[1 \times(4 / 27)+2 \times(4 / 27)+3 \times(6 / 27)+4 \times(7 / 27)+5 \times(6 / 27)] \times 100 / 5=\mathbf{6 5 . 1 8} \%$

Untuk melihat data secara keseluruhan dapat dilihat pada tabel di bawah ini :

Tabel 4 Peringkat faktor-faktor penyebab rework berdasarkan severity index

\begin{tabular}{|c|c|c|c|c|}
\hline $\begin{array}{c}\text { Grou } \\
\text { p }\end{array}$ & No & Variabel-variabel Penyebab Pekerjaan Ulang & SI (\%) & Rank SI \\
\hline I & 1 & $\begin{array}{l}\text { Desain atau dokumentasi yang tidak jelas (Detail tidak } \\
\text { jelas) }\end{array}$ & 65.18 & 7 \\
\hline \multirow[t]{5}{*}{ II } & 2 & Jadwal terlalu padat (banyak pekerjaan lembur) & 51.85 & 15 \\
\hline & 3 & Ketidaksesuaian spesifikasi material & 63.71 & 8 \\
\hline & 4 & Kurangnya antisipasi terhadap keadaan alam & 37.78 & 18 \\
\hline & 5 & Buruknya alur informasi & 56.30 & 13 \\
\hline & 6 & Kurangnya teamwork & 71.11 & 2 \\
\hline \multirow[t]{20}{*}{ III } & 7 & Pekerja kurang berkompeten & & \\
\hline & A & Kurangnya pengalaman kerja & & \\
\hline & & e. Kurangnya pengalaman kerja Tukang & 75.56 & 1 \\
\hline & & f. $\quad$ Kurangnya pengalaman kerja mandor & 65.92 & 6 \\
\hline & & $\begin{array}{lllll}\text { g. } & \begin{array}{l}\text { Kurangnya } \\
\text { lapangan }\end{array} & \text { pengalaman kerja pengawas } \\
\end{array}$ & 53.33 & 14 \\
\hline & & h. Kurangnya pengalaman kerja operator & 70.37 & 3 \\
\hline & $\mathrm{B}$ & Kesalahan dalam menginterpretasikan gambar & & \\
\hline & & d. Pengawas lapangan & 60.74 & 11 \\
\hline & & e. $\quad$ Mandor & 65.92 & 6 \\
\hline & & f. $\quad$ Tukang & 61.48 & 10 \\
\hline & $\mathrm{C}$ & Bekerja tidak sesuai dengan prosedur kerja & & \\
\hline & & c. Tukang & 68.15 & 5 \\
\hline & & d. $\quad$ Operator & 70.37 & 3 \\
\hline & 8 & Kurangnya pengawasan & & \\
\hline & & c. Pengawas lapangan & 44.44 & 17 \\
\hline & & d. Mandor & 50.37 & 16 \\
\hline & 9 & Kurangnya komunikasi & & \\
\hline & & d. Owner dengan kontraktor & 68.88 & 4 \\
\hline & & e. Pengawas lapangan dengan mandor & 57.04 & 12 \\
\hline & & f. Pengawas lapangan dengan operator & 62.96 & 9 \\
\hline
\end{tabular}

Sumber : Hasil analisis

B. Peringkat Faktor Penyebab Terjadinya Rework Berdasarkan Tingkat Kepentingan 
Tingkat kepentingan (Importance Index) adalah peringkat yang diperoleh berdasarkan hasil perkalian antara frequency index dan severity index dari faktorfaktor penyebab pekerjaan ulang pada pekerjaan bangunan gedung yang ada di kota Kupang. Penentuan peringkat didasarkan pada importance index dari tiap faktor. Importance index dapat dihitung dengan rumus sebagai berikut : Untuk faktor penyebab pekerjaan ulang dengan nomor 1, Desain atau dokumentasi yang tidak jelas (Detail tidak jelas). Menurut persepsi responden :

Nilai FI $=42.96 \%$, Nilai SI $=65.18 \%$, IMPI $=[$ FI $(\%) \times$ SI $(\%)] / 100$

$\mathrm{IMPI}=[42.96 \% \times 65.18 \%] / 100=\mathbf{2 8 . 0 1} \%$

Tabel 5 Peringkat faktor penyebab rework berdasarkan Importance Index

\begin{tabular}{|c|c|c|c|c|}
\hline $\begin{array}{l}\text { Gro } \\
\text { up }\end{array}$ & No & Variabel-variabel Penyebab Pekerjaan Ulang & IMPI (\%) & $\begin{array}{l}\text { Rank } \\
\text { IMPI }\end{array}$ \\
\hline I & 1 & $\begin{array}{l}\text { Desain atau dokumentasi yang tidak jelas (Detail tidak } \\
\text { jelas) }\end{array}$ & 28.01 & 15 \\
\hline \multirow[t]{5}{*}{ II } & 2 & Jadwal terlalu padat (banyak pekerjaan lembur) & 28.41 & 14 \\
\hline & 3 & Ketidaksesuaian spesifikasi material & 27.84 & 16 \\
\hline & 4 & Kurangnya antisipasi terhadap keadaan alam & 12.87 & 20 \\
\hline & 5 & Buruknya alur informasi & 37.53 & 10 \\
\hline & 6 & Kurangnya teamwork & 48.98 & 4 \\
\hline \multirow[t]{20}{*}{ III } & 7 & Pekerja kurang berkompeten & & \\
\hline & A & Kurangnya pengalaman kerja & & \\
\hline & & i. Kurangnya pengalaman kerja Tukang & 47.57 & 5 \\
\hline & & j. $\quad$ Kurangnya pengalaman kerja mandor & 44.91 & 6 \\
\hline & & $\begin{array}{llll}\text { k. } & \begin{array}{l}\text { Kurangnya } \\
\text { lapangan }\end{array} & \text { pengalaman kerja pengawas } \\
\end{array}$ & 41.10 & 9 \\
\hline & & 1. $\quad$ Kurangnya pengalaman kerja operator & 49.00 & 3 \\
\hline & $\mathrm{B}$ & Kesalahan dalam menginterpretasikan gambar & & \\
\hline & & g. Pengawas lapangan & 26.99 & 17 \\
\hline & & h. Mandor & 29.29 & 13 \\
\hline & & i. $\quad$ Tukang & 41.89 & 8 \\
\hline & $\mathrm{C}$ & Bekerja tidak sesuai dengan prosedur kerja & & \\
\hline & & e. $\quad$ Tukang & 54.02 & 2 \\
\hline & & f. Operator & 59.42 & 1 \\
\hline & 8 & Kurangnya pengawasan & & \\
\hline & & e. Pengawas lapangan & 22.71 & 19 \\
\hline & & f. Mandor & 24.99 & 18 \\
\hline & 9 & Kurangnya komunikasi & & \\
\hline & & g. Owner dengan kontraktor & 32.14 & 12 \\
\hline & & h. Pengawas lapangan dengan mandor & 32.95 & 11 \\
\hline & & i. Pengawas lapangan dengan operator & 44.77 & 7 \\
\hline
\end{tabular}

Sumber : Hasil analisis 
Vol 3 No 1 (2022), February 2022, pp. 13-23

(C)2022 Jurnal Teknik Sipil Cendekia

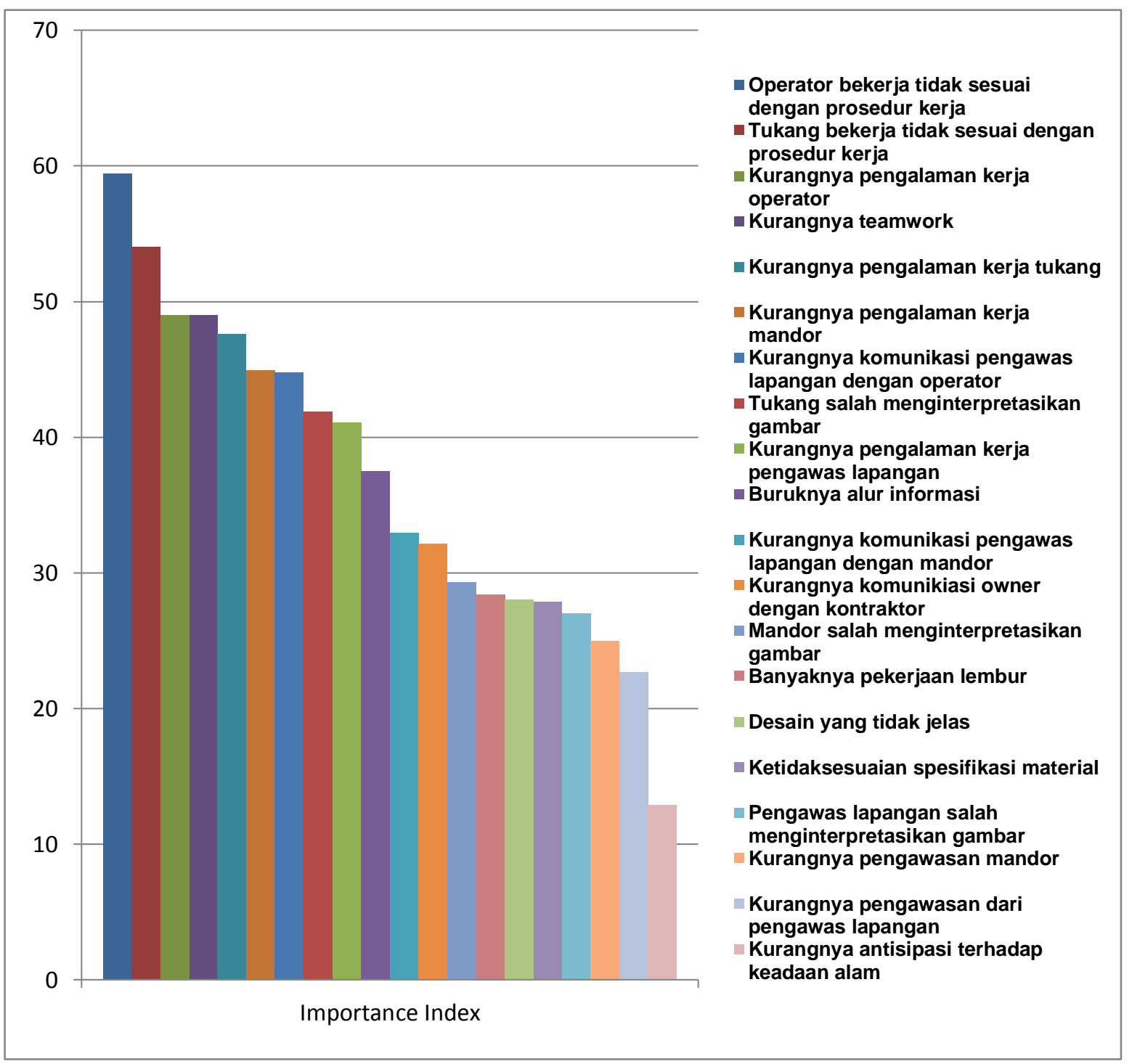

Gambar 4. Peringkat faktor berdasarkan nilai Importance Index

\section{KESIMPULAN}

A. Berdasarkan tingkat kepentingan ( hasil perkalian antara frequency index dan severity index) diperoleh peringkat faktor-faktor penyebab pekerjaan ulang yang terjadi pada bangunan gedung di kota Kupang adalah : 1 . Operator bekerja tidak sesuai dengan prosedur kerja $=59.42 \%$ dari $5 \%$ pekerjaan bangunan gedung. 2 . Tukang bekerja tidak sesuai dengan prosedur kerja $=54.02 \%$ dari $10 \%$ pekerjaan bangunan gedung. 3. Kurangnya pengalaman kerja operator $49.00 \%$ dari $5 \%$ pekerjaan bangunan gedung. 4. Kurangnya teamwork $=48.98 \%$ dari $10 \%$ pekerjaan bangunan gedung. 5. Kurangnya pengalaman kerja tukang $=47.57 \%$ dari $10 \%$ pekerjan bangunan gedung. 6 . Kurangnya pengalaman kerja mandor $=$ $44.91 \%$ dari $20 \%$ pekerjaan bangunan gedung. 7. Kurangnya komunikasi antara 
pengawas lapangan dengan operator $=44.77 \%$ dari $5 \%$ pekerjaan bangunan gedung. 8. Tukang salah menginterpretasikan gambar $=41.89 \%$ dari $10 \%$ pekerjaan bangunan gedung. 9. Kurangnya pengalaman kerja pengawas lapangan $=41.10 \%$ dari $25 \%$ pekerjaan bangunan gedung. 10. Buruknya alur informasi $=37.53 \%$ dari $10 \%$ pekerjaan bangunan gedung. 11. Kurangnya komunikasi pengawas lapangan dengan mandor $=32.95 \%$ dari $45 \%$ pekerjaan bangunan gedung. 12. Kurangnya komunikasi owner dengan kontraktor $=32.14 \%$ dari $10 \%$ pekerjaan bangunan gedung. 13. Mandor salah menginterpretasi gambar = $29.29 \%$ dari $20 \%$ pekerjaan bangunan gedung. 14. Banyaknya pekerjaan lembur $=28.41 \%$ dari $10 \%$ pekerjaan bangunan gedung. 15 . Desain atau dokumentasi yang tidak jelas $=28.01 \%$ dari $10 \%$ pekerjaan bangunan gedung. 16 . Ketidaksesuaian spesifikasi material $=27.84 \%$ dari $10 \%$ pekerjaan bangunan gedung. 17. Pengawas lapangan salah menginterpretasikan gambar $=26.99 \%$ dari $25 \%$ pekerjaan bangunan gedung. 18. Kurangnya pengawasan dari mandor = $24.99 \%$ dari $20 \%$ pekerjaan bangunan gedung. 19. Kurangnya pengawasan dari pengawas lapangan $=22.71 \%$ dari $25 \%$ pekerjaan bangunan gedung. 20 . Kurangnya antisipasi terhadap keadaan alam $=12.87 \%$ dari $10 \%$ pekerjaan bangunan gedung.

B. Solusi / rekomendasi

Setelah membaca dari berbagai sumber penelitian antara lain dari jurnal-jurnal tentang rework dan sumber buku terkait, maka diberikan beberapa solusi terkait persoalan utama yang dihadapi antara lain :

1. Tukang dan operator bekerja tidak sesuai dengan prosedur kerja dan kurangnya pengalaman kerja.

Tukang dan operator merupakan sumber daya utama yang ada di proyek. Karena itu sumber daya ini perlu diperhatikan khusus jika menginginkan agar proyek tepat waktu, tepat mutu dan tepat biaya. Namun berdasarkan data yang diperoleh pada daerah penelitian, sumber daya ini juga merupakan penyebab terjadinya rework, sehingga perlu mendapat perhatian khusus. Perhatian yang dimaksud antara lain dengan cara :

a. Mengadakan pelatihan atau pendampingan bagi tenaga kerja .

Tukang dan operator perlu diberi pelatihan atau pendampingan yang cukup (terutama kepada tukang dan operator yang belum cukup berpengalaman).

b. Kontraktor perlu melakukan kontrak kerja dengan tukang dan operator sehingga dapat diberi pelatihan atau pendampingan dengan baik dan benar.

c. Meningkatkan pengawasan di lapangan oleh mandor dan pengawas lapangan sehingga apabila terjadi kebingungan atau ketidaktahuan, pekerja langsung menanyakan kepada pengawas lapangan atau mandor sehingga pekerja tidak bekerja dengan keinginan sendiri yang akhirnya bekerja tidak sesuai dengan prosedur yang berdampak pada pekerjaan ulang (rework).

2. Kurang Teamwork

Responden setuju untuk menempatkan faktor kurangnya teamwork sebagai penyebab rework. Kurangnya kerja sama antara pihak-pihak terkait dalam proyek, terjadi sebagai akibat sistem procurement yang dipakai dimana pada umumnya yang dipakai 
di Indonesia adalah sistem tradisional (desain-tender-bangun). Sistem tradisional ini telah berulang kali disebutkan sebagai salah satu penyebab utama buruknya koordinasi antara kontraktor dan konsultan. Rata-rata responden kontraktor pelaksana memberikan nilai tinggi kurangnya teamwork pada pembangunan gedung di kota Kupang (Ranking 4). Oleh karena itu untuk kasus ini pendapat yang dikemukakan bahwa kontraktor melihat kerja sama antara pihak lain dengan pihak pemilik proyek belum berjalan maksimal. Komunikasi dan koordinasi kurang terjadi pada masa awal proyek (fase awal desain) akan menyebabkan terjadinya perubahan desain yang akan menimbulkan rework. Solusi yang dapat diberikan untuk kasus ini antara lain :

a. Dari pihak owner perlu membangun komunikasi dan koordinasi dengan pihak lain agar terjalin kerja sama yang baik dari masa awal proyek hingga pada akhir waktu penyelesaian.

b. Kontraktor juga perlu membangun kerja sama dengan pihak-pihak terkait apabila pekerjaan berada dalam kapasitas yang besar, dalam hal ini kontraktor mengadakan sub-kontraktor untuk membantu menyelesaikan pekerjaan dalam kapasitas yang besar.

c. Pihak desainer dalam hal ini konsultan perlu menjalin kerja sama yakni komunikasi yang baik dengan kontraktor maupun owner guna menyelesaikan pekerjaan pembangunan gedung. 
Vol 3 No 1 (2022), February 2022, pp. 13-23

(C)2022 Jurnal Teknik Sipil Cendekia

\section{DAFTAR PUSTAKA}

Dipohusodo, Istimawan. 1996. Manajemen Proyek dan Konstruksi. Yogyakarta : Kanisius

Erick, et al.,2014.Model dan Sumber Penyebab Rework pada Tahapan Proyek Konstruksi. Glasglow. Volume 3, No.4

Henong Sebastianus, 2016. Analisis Faktor-Faktor Yang Mempengaruhi Keterlambatan Pada Proyek Pemerintahan Di Kota Kupang. Prosiding Seminar Nasional Teknik Sipil, Fakultas Teknik Universitas Muhammadiyah Surakarta, 2016 ISSN: 2459-9727

Hidayat A, et al., 2010. Faktor-faktor Penyebab Pekerjaan Ulang (Rework) yang Berkaitan dengan Manajerial pada Proyek Konstruksi Jalan di Kabupaten Rokan Hulu.CED.Volume 1, No.1

Juliana H. Februari 2011. Kajian Pola Rework pada Pelaksanaan Pekerjaan Finishing Perumahan di Surabaya. Prosiding seminar nasional manajemen teknologi XIII. Volume 7, No.2.

Kukuh, et al., Juli 2011. Analisa Rework pada Konstruksi Gedung di Kabupaten Bondowoso. Prosiding seminar nasional manajemen teknologi XIV. Volume 8, No.1.

Nurhayati.2010. Manajemen Proyek. Graha ilmu : Medan

Prianto, Kusnul. 2012. Analisa Faktor Penyebab Pekerjaan Ulang pada Proyek Konstruksi di Kota Malang. Alfabeta. Volume 10, No.2.

Rahmatul, et al., Agustus 2012. Faktor-faktor Penyebab Pekerjaan Ulang (Rework) pada Pembangunan Gedung Dinas Bina Marga dan Cipta Karya Unsyiah. Pasca sarjana universitas syiah kuala. Volume 1, No.1.

Reksohadiprodjo, Sukanto.1983. Manajemen Proyek. Yogyakarta : BPFE

Ryan Ariefasa. Faktor Penyebab Keterlambatan Pekerjaan Konstruksi Bangunan Gedung Bertingkat yang Berpengaruh terhadap Perubahan Biaya pada Pekerjaan Struktur. Skripsi Program Sarjana Strata I Universitas Indonesia. Jakarta, 2012

Santosa, Budi. 2008. Manajemen Proyek. Surabaya : Graha Ilmu

Sugiyono.2013. Metode Penelitian Kombiinas. Bandung : Alfabeta

Sugiyono.2014.Metode Penelitian Pendidikan..Bandung : Alfabeta

Sugiyono. 2013. Statistika untuk Penelitian. Bandung : Alfabeta

Sutrisna, et al., Juli 2013. Analisis Rework pada Proyek Konstruksi Gedung di Kabupaten Bandung. Alfabeta. Volume 1, No.2

Yuni, et al., 2013. Faktor-faktor Penyebab Pekerjaan Ulang (Rework) pada Proyek Gedung di Kabupaten Rokan Hulu berdasarkan Persepsi Kontraktor.CED.Volume 1, No.1. 